\title{
Voyage in the "Beagle"
}

\author{
SUZANNE T CHAPMAN
}

Not so much a student elective, more a postgraduate one. ... I spent a year at sea in a very different sort of way.

You may have seen the seven-part BBC drama-documentary series "The Voyage of Charles Darwin" and noticed the Beagle vessel so prominently featured. Those were the days before the spending axe came down, and this little ship was chartered to sail around South America (fig 1).

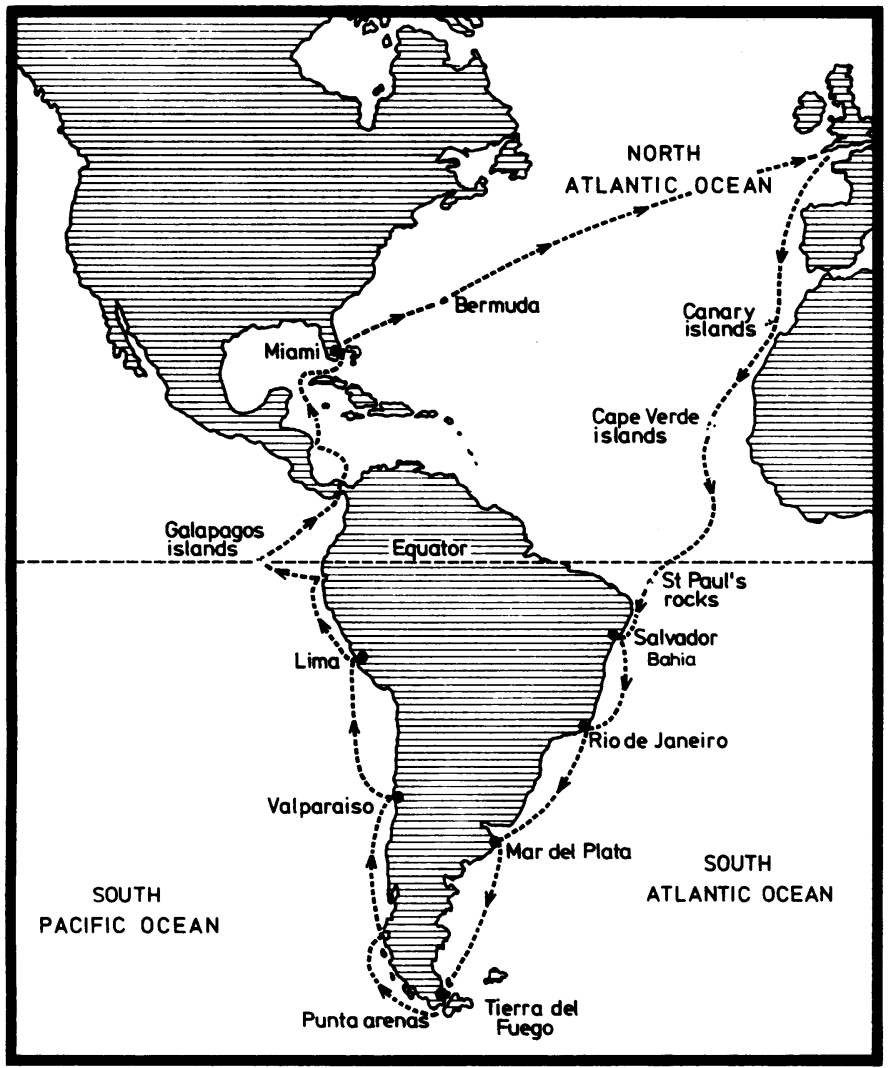

FIG 1-Route of HMS Beagle.

\section{Doctor, caterer, and cook}

How did I get involved? In the usual search for post-intern jobs someone showed me the advertisement that read: "Wanted -sailing doctor for voyage around South America." To cut a long story short, I got the job, and also landed myself as caterer and cook.

The pre-departure days were frantic. The ship, the Marques, was a $90 \mathrm{ft}$ brigantine built in Spain in 1912, and was owned by a partnership-one an enthusiastic ex-film director/farmer, the other an ex-Naval officer. Working night and day to have her ready on time was a pack of Cornish "lads" from her home port of Charlestown. Some were to form the nucleus of her crew.

Division of Pathology, Southmead General Hospital, Westbury-onTrym, Bristol BS10 5NB

SUZANNE T CHAPMAN, MB, DTM\&H, senior house officer (present appointment: registrar in microbiology, Southmead General Hospital)
I was to organise the medical and food supplies. The Royal Naval Hospital, Plymouth, kindly supplied an entire minipharmacy and a huge chest (more suited to a mine-sweeper), which contained everything from an eye-patch to a hot-water bottle. Food I amassed from sponsors and also bought vast quantities from the local cash and carry.

Amid the chaos of last-minute finishing off, we set sail from Charlestown on 26 July 1977. The ship had been converted from a brigantine to a barque (with two square-sailed masts and an aft' mizzen) and had new paint-work, spars, rigging, and figure-head. She had been transformed to HMS Beagle in just six months (fig 2).

Our first landfalls were the Cape Verde Islands and later St Paul's Rocks on the Equator-both of which were visited by Darwin on the original voyage in 1882 . In between times the crew had time to mould and adapt now that the pace had slowed to that of ocean life. Her complement of 16 included a rigger, a carpenter, a potter, a professional (canvas) sail-maker on loan from the Royal Navy, and even an ex-racing driver. I was to be the only woman-I doubt if Captain Fitzroy would have approved-but I did have plenty of sailing experience from my college days in Ireland and was used to the sea. We got on well as a group and followed the classic patterns of small-group behaviour as the voyage progressed.

\section{Ills and pills}

I was not, however, to be their psychiatrist-I was more concerned with their physical ills. It proved true that "common things are common." In surgery after breakfast there were often cuts and splinters to attend; aspirins and the like were the most used drugs. In the tropics the crew were warned of dehydration and the need for salt replacement. Besides extra salt in the cooking and with food I had salt tablets (and also ascorbic acid tablets) freely available. Sea-sickness was sometimes a problem (fortunately I have a cast-iron stomach). Standard sea-sick pills were often ineffective against the ship's wide rolling motion. I even, in my enthusiasm, brought intramuscular preparations but soon realised that these are neither practical nor popular on smaller boats. Most people had their own

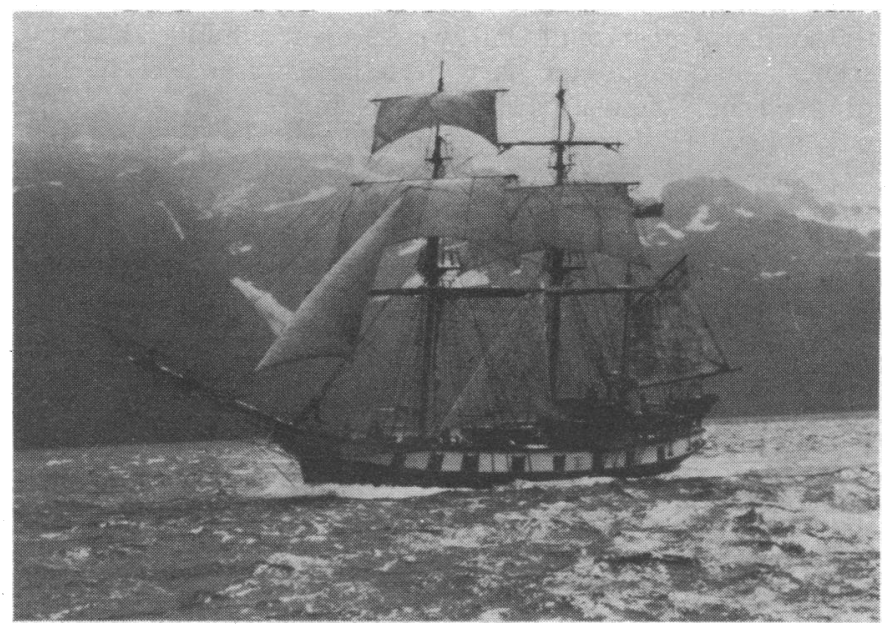

FIG 2-HMS Beagle. 
remedies-for instance, quietly "dying"-and recovered. The only guaranteed cure is to sit under a tree.

Infections did occur-from colds, a urinary tract infection, infectious mononucleosis (two cases, six months apart, confirmed by on-shore laboratory facilities) to the more intimate varietydoubtless resulting from the more over-friendly members of the South American population. One case of Bell's palsy responded well to oral steroids. Diarrhoea (and constipation) was a frequent but minor problem, but unlike the largely shorebased film unit we had no cases of parasitic origin. My only "tropical case" was a member of the film unit whose arm had been bitten by mosquitoes in Brazil. Large painful swellings developed that had been diagnosed as boils on several occasions. When she saw me three months later in November they showed no signs of improvement. Gentle pressure extruded a perfect third-stage larva of the American warble fly (Dermatobia hominis) from each of the two "boils." The eggs of this fly are carried on the undercarriage of the mosquito and on contact with a warm-blooded animal the larvae quickly emerge and burrow subdermally to develop.

Much to my relief, there was no major trauma, despite the crew's constant acrobatics in the rigging while sail changing. I did have dried plasma and plasma expanders on board if the worst should occur; we were usually in daily radio contact with Portishead and within a few days' reach of shore. The only times we would be on our own were the 21-day Atlantic crossings. That was just when I fractured my mandible. No-I hadn't been socked for a bad meal-the hammock our sail-maker had made me had simply turned turtle during the night and deposited me squarely chin-first on the deck. A radiograph in Brazil 10 days later confirmed my diagnosis. (Luckily I had good contacts, a good reduction, and a diet of Brazilian rumlime cocktails for the next five weeks.)

\section{Food, flora, and fauna}

There were fewer feeding problems for the crew once I had learnt to gauge my recipes to their appetites and adapt to the whims of the ship's solid-fuelled Aga cooker. Fresh meat, fruit, and vegetables were bought in port when possible. We had problems with our freezer, which became defunct after the first month at sea, and we sometimes had to rely on large fresh fish pulled from the briny. The tropics yielded marvellous fruits: huge bunches of bananas (beware-they ripen at once), pineapples, papayas, mangoes, and fresh green limes. When we went on to the cold south the bread consumption doubled, and I had to hide my daily bake. I doubt if their diets were deficient.

As for the voyage we had no big storms, only engine troubles, and always we had deadlines to meet. The BBC film unit and actors met us in Salvador (Brazil) and filmed with us in September. We then progressed via Rio de Janeiro and Mar del Plata in Argentina down to Punta Arenas in November. Here in the southern-most tip of Chile we discovered unique and mystic scenery that could not have been faked elsewhere. Glaciers dropped into desolate beautiful channels-with a snow-line only a few feet above sea-level (an effect of the cold Humboldt current). Dense foliage of mosses, lichens, and the twisted Austral beech completed the back-drop. Once filming was over we were left to continue through the maze of channels into the Southern Pacific. (To my everlasting regret we did not go round the Horn though within a day's run from it.)

Soon we were back in the sun, and Christmas was spent' in Valparaiso. Our journey then took us further north via the Robinson Crusoe (Juan Fernandez) Islands, Peru (Lima), and Guayaquil, the humid mosquito-ridden port of Ecuador, to our final film rendezvous at the Galapagos Islands in March. Though on the Equator, these islands are cooled by the continuing effect of the Humboldt current from the south. The island group is a strictly kept Ecuadorian nature reserve and visiting yachts are normally allowed to remain for only 72 hours.
It took 18 months of negotiation to get permission to film there. They are bizarre, enchanting volcanic islands-not the lush tropical paradise that many people imagine. The animals are extraordinary and totally unafraid of man (as opposed to being tame). Many indigenous species are found nowhere else in the world-including a Galapagos penguin.

\section{Mission completed}

Our mission completed, we sailed back to England via Panama, Mexico, Miami, and Bermuda-our last landfall before home. Excitement mounted as we neared the Cornish coast in June 1978-almost a year since our departure from the same tiny harbour. There was much jubilation on our returnyet a tinge of sadness, for we knew we could never again experience the same bond that distinguished us from "shore" folk. The spell was broken.

Now over a year since our return and safely back in the medical world I can look back on the experience from a different angle. It was difficult to readjust. We had had our bad times: being shot at in Argentina, nearly running aground on a coral reef in the Caribbean, and everyone had their "down" moments. But one remembers the good times: being constantly surrounded by a shimmering blue sea, swimming over the side in warm deep water, the high-pitched sounds of the friendly dolphins swimming alongside, and the nights under the Southern Cross, with the albatross by day wheeling in our wake. I remember too the people we met: colourful Brazilians, hospitable Chileans, Peruvian Indians-all sorts. ... I could become a bore.

Some of the crew are still with the ship. There is a temptation to fall back to this escapist life but I realise that, for me at least, it could never become permanent. I do think, however, that everyone should experience it-if only to set the civilised humdrum we live in in perspective.

(Accepted 14 May 1980)

WORDS STRESSES and STRAINS. These terms are commonly used with no clear understanding of their respective meanings. Indeed, they are often used interchangeably, or in common parlance lumped together as in the phrase "stresses and strains," and virtually given the same meaning. The basic meanings of stress and strain are most clearly defined in terms of mechanics, where stress is the force applied and strain is the resulting change, whence by analogy these meanings may be extended to physiology, psychology, and clinical medicine. Thus disagreeable events or conditions in a man's occupational or domestic life are stresses, and the resulting palpitations, hypertension, anorexia, or duodenal ulcer are strains. The fact that in general the laity, apart from engineers, may fail to distinguish these terms is no ground for the medical profession to use a similarly confused terminology. That there is a realisation of the present confused state is evidenced by a discussion that took place at the CIBA Symposium on the Cardiovascular, Metabolic, and Psychological Interface held at Stratford-upon-Avon in December 1978.

I quote, "V Hrubes: "In the past there has been much misunderstanding of the word "stress," which is commonly used to describe both the cause and the syndrome of reactions-that is, the response. Lately the term "stressor" has been employed for the cause.' M Lader: "We have to accept that "stress" is now used mainly to describe the response. We should avoid using it for the external stimulus as well-the "stressor." However, we assume that any powerful stimulation must be a "stress," and that any "stress" response must be the result of such stimulation. We could with advantage avoid the term entirely and speak of stimulus and response.' "'

I regard as unfortunate any attempt to introduce a new word (stressor) and misuse an old one (stress) when the entirely satisfactory words, stress and strain, already exist.-B J FREEDMAN. 